\title{
«Clinical psychology in the case of an emergency : the position of the psychologist confronted with psychic trauma. A clinical case to illustrate the importance of the implicit demand in the development of post-traumatic stress disorder. »
}

\author{
FRAUD Aurélie \\ Hôpital Pasteur, CAP \\ 30 Voie Romaine, 06000 Nice (France)
}

\begin{abstract}
Confronted with events of a high traumatic potential that our Earth is experiencing: wars, terrorism, attacks on people of all kinds etc ... Emergency clinics have become essential in the care of populations. Emergency shelters, as well as emergency cells, have been developing strongly in recent years. The victims are looking for a response to their inability to elaborate upon the event. There, the place of clinical psychologists can become essential. We will see through a clinical case, how positioning and listening to a professional can allow the emergence of the implicit demand by the subject. By this assumption, not of the event but of the subjective experience of the event by the person, the clinician based on psychoanalytic theories could allow the subject to reduce the risk of developing a post-traumatic stress disorder.
\end{abstract}

Keywords : Clinical psychology, Trauma, Emergency Clinic, Implicit Request, Clinical Positioning, Post-traumatic stress disorder.

\section{Introduction}

In this article, we wish to share with you our experience and our questions about the place of the clinical psychologist in a situation of crisis or emergency. It is in departments such as psychiatric emergencies (CAP : Psychiatric Reception Center), or in the deployment of medical-psychological emergency cells, that we are asked whether a mental health professional can have a major role in the development of the psychic trauma in the subject. Relying on the psychoanalytic approach, we believe that what creates suffering within the subject is not the potentially traumatic event reported at first by the subject, but the way in which the event was subjectively viewed. More specifically, what, in the traumatic scene, leads to a psychotic break? In fact, we asked ourselves the following question : in the urgency and in the face of the psychotic staggering caused by the trauma, where should the place of the clinical psychologist's listening be? It is beyond the traumatic scene that will lead us our meeting with Cali, inscribing the implicit demand at the heart of the exchange. Its necessary emergence, its understanding by the clinician and its assumption would offer about the possibility that the psychotic intrusion the subject has gone through has no major repercussions on her homeostatic psyche.

\section{Trauma: From a psychiatric definition to its psychoanalytic comprehension}

In our Postmodernity which reflects the horror of the treatment that man inflicts on his fellows, psycho-trauma is at the heart of the problems encountered by mental health professionals. More and more frequently, we find ourselves facing patients in crisis, looking for answers to their evils, both somatic and psychotic. This strong increase in demand pushes us to re-question the concept of psychic trauma, be it from a psychiatric and/or clinical point of view of the term, and of course the position of mental health specialists in this particular context.

In the DSM $\mathrm{V}^{1}$, the state of post-traumatic stress is defined by a series of visible symptoms: reviviscence, avoidance, persistent negative alterations in cognitions and mood, and by hyper reactivity. This manual does not refer to the diagnosis of post-traumatic stress disorder unless the symptoms persist beyond one month after exposure to the traumatic event, otherwise it is seen to be a state of acute stress.

\footnotetext{
${ }^{1}$ DSM V (Diagnostic and Statistical Manuel of Mental Disorders. 5th Edition), (2015). Arlington VA. American Psychiatric Association 2015. DSM-5 - Manuel Diagnostique Et Statistique Des Troubles Mentaux American Psychiatric Association, Traduction française coordonnée par Marc-Antoine Crocq, Traduction française coordonnée par Julien-Daniel Guelfi, Traduction française coordonnée par Patrice Boyer, Traduction française coordonnée par Charles-Bernard Pull, Traduction française coordonnée par Marie-Claire Pull Editeur: Elsevier Masson
} 100 
Dissociation, whether it affects cognitions, behaviours etc. is at the heart of the traumatic problem, and that is what will be revealing for the psychiatrists of the traumatic component in the subject. At the outset we understand that the psychic suffering treated by psychiatry aims primarily at the relief of apparent symptoms.

In psychoanalytic theories, Freud ${ }^{2 / 3 / 4}$ first of all distinguishes what is related to the trauma and what refers to psychic trauma. For him, the trauma corresponds to the traumatic event and the traumatisation would correspond to the subjectivity of this event by the individual. That is, the psychic trauma (traumatism) would correspond to the representation by the subject of the potentially traumatic burden that an event is creating. For Lacan ${ }^{5 / 6}$, this distinction between the traumatic moment and its representation reveals a flaw in the meaningful chain, constantly recalling this "nonsense" that patients send to us during our encounters. Without resolving the question of « why it happened/why do I feel like this? », the patient encysts the traumatic problem in his psyche, registering it as a symptom in his daily life. The crystallisation of the subject makes him the spectator of his own life, that he can no longer take control. In this context, we understand that the clinician could become the one that apports sense where there was previously only misunderstanding.

\section{Case Study: Cali}

\section{1) Our meeting with Cali}

Cali is a 21 year old Ivorian woman. We met her as part of our consultations at the psychiatric reception center (CAP). Cali is accompanied by a team of firefighters. We are surprised by her light clothing in the middle of winter. She seems neglected, lost, disoriented, and has empty stare. Her disturbed and distraught appearance led her to wander, which is why we believe the firefighters had led her to the psychiatric emergencies centre. Physically exhausted, she seems much older than she really is, as if life had already worn her down. Cali comes to CAP, completely staggering. The psychiatrists propose that we meet her first, believing that our activities in the servicing "Psycho-trauma » would clarify the discourse and the situation of the young woman.

Cali arrived in France four years ago, alone, leaving the rest of her family in Ivory Coast. She lives with her one year old son and his father, whom she says she trusts. Yet she never mentions his name during the interview. She is, at the time of our meeting, two and a half months pregnant.

The trigger of her current state was the discovery via a social network, the day before our encounter, of a photo of her brother who had been hanged. She had been informed of the death of the latter two weeks before. Cali admits she doesn't know how she ended up here. Nevertheless, she admits : I saw the picture of my little brother, he was hanged», miming what she remembers of his posture in the image. To do this, from her right hand she lowers her turtleneck, draws the line of the rope with his finger and mimics the extension of the rope along her head leaning to the side, mouth open. She repeats this mime many times during the interview, describing each of her gestures. A description at the height of an attempt to rebuild the traumatic scene, or symbolisation of this reality that causes trauma to Cali. Bewildered, the young woman seemsunaffected. She limits herself to the description of the image. According to us, this seems to be symptomatic of a dissociative state. In a counter-transferential way, we are absorbed by this state of shock and by the ritual that punctuates the beginning of each of its sentences. This "Madame ", which she constantly follows with a long silence is heavy for her interlocutor, and accentuates the discomfort.

This significant («Madame») not devoid of neutrality, she seems to summon us to a maternal place where she can, or wants to entrust her word. Does this allude to the woman/mother that would be able to keep her composure?

In any case, each word pronounced seems to weigh upon her heavily. Metaphorically, this would justify long silences between her sentences, as if the word had something burning, agonising, requiring the mobilisation of all her remaining psychic abilities. It paradoxically gives the impression of being afraid to aggravate these evils by the words she verbalises. Yet without saying a word, she only hurts the one she doesn't seem to want to identify with. Would her verbal expression risk of addressing the other's suffering? Or would it expose the risk of losing the pleasure that it provides for her by retaining this pathological nucleus within herself? This guides us towards the hypothesis of a regression at the stage of anal or sadistic development.

\footnotetext{
${ }^{2}$ FREUD S., BREUR J., (1895), Études sur l'hystérie, OCF II, Paris, PUF

${ }^{3}$ FREUD S., (1923), Au-delà du principe de plaisir, OCF V, Paris, PUF

${ }^{4}$ FREUD S., (1926), Inhibition, symptôme et angoisse, OCF VII, Paris, PUF

${ }^{5}$ LACAN J., (1968-69) Le Séminaire, livre XVI, D’un Autre à l'autre, Paris, Seuil

${ }^{6}$ LACAN J., (1973) Le Séminaire, Livre XI, Les quatre concepts fondamentaux de la psychanalyse, Paris, Seuil
} 
Regarding this photo, Cali tells us that she obtained it «from a friend who saw her on Facebook». This would've dissuaded her from looking at it, seeing Cali's insistence. She tells us «not to believe it», since her mother had already told her that her «little brother had died due to sickness». These words were then proven false as evidenced by the following: «I spoke to him the day before he died on the phone, someone who was sick, would have told me. » She remembers precisely the last words that her little brother entrusted to her « our mother is our worst enemy » before that « someone had taken the phone from his hands ». From his, Cali reveals this transferential relationship, the fragility of her ties to her mother, those even at the origin of the inhibition of her development abilities. From this paradox between the love of the mother and the rejection of the same mother who became the «enemy » (following the denunciation of the deceased brother), the question arises of the origin of the trauma developed within Cali. In other words, could this traumatic issue seemingly triggered by the discovery of the photo of her little brother, rather be the result of the confrontation of the terrifying image of a murderous mother than the sight of her hanged brother?

Cali feels « guilty» for not being present for her little brother. She tells us that she «left him alone » with her mother, because, she was «forced to marry a man» from whom she «escaped/fled» in 2014 to come to France. Cali tells us that she has five other siblings, older than her, but they «all died in front of » her (without providing any further information or detail). This information keeps us in the dark because she only speaksbriefly about this loss during the interview, mainly referring to the deaths of her father and her little brother.

She then gives us more detail on the circumstances of the loss of her five other brothers, to clarify that « they died just like that, eating, [and they were] poisoned. » She evokes many « horrible nightmares » following these deaths, without telling us anything more despite our solicitations. She simply repeats that she is «alone » now, and that « only my little brother and I remained. »Concerning the death of her father, Cali evokes the scene: « he was in the shower, and asked his wife, my mother, for water. She must've put something in the water because he screamed as he put the water on his sex, it's like it had cut him. » She confides that after that her father " disappeared », he must've " gone to another city », and deplores «I have never seen him again ». However, she talks about their last telephonic exchange, in 2013, « his last sentence was "your own mother is your worst enemy" and then, someone took the phone from his hands. » Cali continues « he was murdered, he was poisoned. » She wonders for a long time about this similarity between the two situations, directingher question to us « in whom I can trust? » I feel betrayed ». Thus, beyond her confrontation with the photograph of her late brother and the unbearable disappearance of her father, that is, beyond the question of death, it would seem that the real frightening element for Cali would be her lack of knowledge relative to the unspeakable question « is the Other capable of killing? » This unbearable question that she transmits to us in the encounter summons her faith in an attempt to elaborate, "God gave him life, the same God has taken him back », then « if it is God who wants it... ». This self-intellectualisation by the subject would aim, through discourse, to master their internal conflicts and emotions.

When Cali arrives, her stare is totally empty and flees upon eye contact. At the beginning of the interview, she speaks in a low voice, so much so that it is necessary to utilise all our attention to hear it. Cali displays, defensively, a total detachment of her affects. The question that arises is; what in this situation actually inhibits the affects of the young woman to manifest. Is it the real inability of the subject to express them or is it a defensive modality, a self-preservation technique with the vocation of protecting her psychic apparatus from traumatic intrusion?

\section{2) Transfer}

At the end of the interview, Cali no longer verbalises suicidal thoughts having « heard » what has been brought brought forward. She tells us she is determined to « fight » for « justice to be served » for death of her father and her little brother. Her speech is more fluid, her verbal fluency much more regular, and her gaze is no longer fixed and fleeting. She lights as when we tell her that «we are here for her » and that «it seems important to us that she takes time to think only of herself. So, we propose that she "stays here for the night."» Although reluctant at first to the idea, she accepts thinking that her companion could take care of her son. Cali, who seems to "revive" her mother's evocation, portrays her as a traitor in the family clan. At the death of her relatives, brothers and father, she can only refer to the explanation that had been brought to her by them before their absence, before this hole left by their loss. By the death of her father, Cali sees a fracture in the Oedipal scheme : there is the loss of the first object of love, which, if followed by the classical pattern, should be neglected in favour of an identification in the maternal figure. However, the psychic state which Cali occupies during our meeting puzzles us. She seems to have experienced cumulative trauma related to the many losses she has suffered, but until then, internal homeostasis appeared to be maintained. How could we accept the fact that her clinic at the time of our meeting emerges only after discovering the photo of her little brother? She tells us that without him, there is only her, alone with her mother. Although we had little information about her relationship with her younger brother, it would seem that a transfer of 'the object of love' had been effected from her father to her brother upon the death of the first. The Oedipian triad, although disturbed, was maintained. This triangulation arises as an impossibility to be after the death of her brother.

102 
There would no longer be a paternal figure embodying the object of love, which was immediately lost. Therefore, this « worst enemy » that her mother embodies cannot be taken as an identification figure without it confronting her with its treacherous signification. In fact, we could hypothesise that Cali's hatred of her mother would reflect her refusal to identify with her.

\section{3) From counter-transfer to the maternal place}

Even though Cali verbalisessuicidalideas, we seize her request by repairing the failure of the Other maternal. This experience allowed us to question the place of the clinical psychologist in a Psychiatric Emergency Department. This question in turn encompasses that of the clinic in one session and how we can hear the complaint, the request and the psychic suffering of the subject in this context.

Cali only revealed her psychic emptiness. She seemed to be dead to us, rigid if we were to refer to the corpse. Additionally, at the beginning of the interview, she verbalisessuicidal ideas saying she wants to «be finished »with not knowing «what to do ». The largely dominant death drive during the interview summons us counter-transferentially a desire to favour the necessity of a return to a homeostasis of the pulsionnal field, to contain the unbearable nature of the encounter. It highlights the state oftrauma Cali is in, by the by the presence of repetition in her speech. It was as if we wanted to "inject life" into her, when we remind her that "God gave her a son, and another waits for his first cry ». This willingness within us, throughout this clinical encounter, was not unrelated to what Cali had come to address. Beyond the question of death, and more particularly suicidal logic, it was the question of loss and abandonment that seemed to fuel her traumatic dimension. Left alone by her partners, it was only by expressing the sense of betrayal by her mother that Cali resumed life punctually. In these rare moments, which mobilise something of the order of her subjectivity, Cali calls upon us to speak about her mother. There, her affects seem to regain a place in her dynamic, with hatred in the foreground «my mother destroyed us ».

During this meeting we took it to heart to accompany Cali to the point of getting back into the impulse of life. Because, her painful situation summoned a feeling of injustice within us. We hoped to give life, a second time, to this who had lived so many painful experiences throughout her existence.

\section{Result}

We asked to follow the care of Cali during the four months following our first meeting, we then leftthe institution. The objective of this monthly follow-up was to allow Cali to have a moment of free speech to allow her to better elaborate upon the different griefs that confronted her, but especially to follow her evolution in the pattern of development of the post-traumatic stress disorder as defined by the DSM V. What we noticed from our second meeting and confirmed in the following, is that no post-traumatic event appeared within Cali. Any kind of psycho-trauma does not necessarily lead to a post-traumatic stress disorder, and its development varies according to the temporality of each. However, no behaviours of avoidance, hyper reactivity and/or flashbacks appear in Cali during the entirety of our encounters. In fact, we could question the success of the first meeting : is the capacity and assumption of the implicit demand detected by the clinician not to avoid the fact that the traumatic nucleus crystallizes?

\section{Discussion}

In a department like the CAP, the emergency clinic is the most important part of our activity within this structure : it seems necessary to distinguish quickly what would be of the order of "true and false". We do not speak in terms of the truthfulness of words, if not in a wager made by the professional on the suffering of the subject met. The professional embodies an investigator to try to find out whether, in the face of the remarks reported by the subject, they must be considered a vital emergency or rather to be revealing an implicit demand. In other words, it is necessary to be able to quickly orient the subject, the question is to distinguish between what is the order of the passage to the imminent act, a call for help relating to a specific questioning of the subject. Thus, this dynamic puts us directly in the face of the necessary assessment of suicidal risk. This leads us to question the role of the clinical psychologist in this emergency clinic, which is part of Psychiatry. More broadly, this issue in turn encompasses that of the clinic in one session and how we can hear the complaint, the demand and the psychic suffering in the subjects in this context.

Cali comes to us in a state of important psychic sideration and in the absence of the link to the Other to which it can no longer make sense. It relates to an event with a strong traumatic potential for us, which can lead to the clinician's fascination and the desire for sensationalism. But should the clinical psychologist be content with this form of voyeurism to deal with psychic suffering, where should he push the patient to reflect on the suffering he expresses? 


\section{Conclusion}

Beyond our theoretical and scientific knowledge of post-traumatic stress disorder, we realised through our clinic, that the assumption of psychic sideration in the first moments following the event could prove to be an unavoidable necessity. It is not a question of getting the patient to talk about what, for us, would reflect the sensational, but his way of going through the potentially traumatic moment. From there, it is no longer a question of treating the symptom in the psychiatric sense of the term, but what comes to manifest the symptom in the subjective experience of the individual. To do this, Cali taught us to go beyond our representations to listen to a speech that would have been inaccessible if we hadn't shifted away from the traumatic event. This work has shown that what the patient is asking for in emergency services is not a treatment of a visible symptom, but the ability of the interlocutor to hear what is in the order of the unspoken, to see beyond wounds the internal and singular wound that comes to manifest itself. The clinician's response to this emergency care is to provide a bracing on the subject, providing a specific clinical listening to the implicit demand that the patient is attempting to express. In the event that the clinician's response to the trauma experienced by the subject allows the latter to give meaning to his affects, we observe the retaking of the significant chain and therefore the possibility of the patient coming out of the vicious circle that would crystallise the traumatised nucleus. Without developing post-traumatic symptoms during the following months our first meeting with Cali, we may think that the clinician in a Psychiatric Emergency Department can have a major role in reducing the possibility posttraumatic stress disorder of the subjects involved.

\section{References}

DSM V (2015), Diagnostic and Statistical Manuel of Mental Disorders. 5th Edition Arlington VA. American Psychiatric Association. DSM-5 - Manuel Diagnostique Et Statistique Des Troubles Mentaux American Psychiatric Association, Traduction française coordonnée par Marc-Antoine Crocq, Traduction française coordonnée par Julien-Daniel Guelfi, Traduction française coordonnée par Patrice Boyer, Traduction française coordonnée par Charles-Bernard Pull, Traduction française coordonnéepar Marie-Claire Pull Editeur: Elsevier Masson

FREUD S., BREUR J., (1895), Études sur l'hystérie, OCF II, Paris, PUF

FREUD S., (1923), Au-delà du principe de plaisir, OCF V, Paris, PUF

FREUD S., (1926), Inhibition, symptôme et angoisse, OCF VII, Paris, PUF

LACAN J., (1968-69) Le Séminaire, livre XVI, D’un Autre à l'autre, Paris, Seuil

LACAN J., (1973) Le Séminaire, Livre XI, Les quatre concepts fondamentaux de la psychanalyse, Paris, Seuil 